\title{
CORRECTION
}

\section{Correction to: Development of a design platform for the high-range sprayer used for street trees based on a VR visualization}

\author{
Published online: 14 September 2021 \\ (c) Springer-Verlag France SAS, part of Springer Nature 2021

\section{Correction to: \\ International Journal on Interactive Design and \\ Manufacturing (IJIDeM) \\ https://doi.org/10.1007/s12008-021-00757-1}

Jipeng Chen ${ }^{1} \oplus \cdot$ Minghong Shi ${ }^{1} \cdot$ Hongping Zhou ${ }^{1} \cdot$ Jun Chen $^{2}$

Authors would like to correct the incorrect references. The references were renumbered and corrected.

The original article has been corrected.

Publisher's Note Springer Nature remains neutral with regard to jurisdictional claims in published maps and institutional affiliations.

The original article can be found online at https://doi.org/10.1007/ s12008-021-00757-1.

\section{Jipeng Chen}

cjp@njfu.edu.cn

1 School of Mechanical and Electronic Engineering, Nanjing Forestry University, 159 Lonpan Road, Nanjing, China

2 Nanjing Xianji Technology co. LTD, 118 Chengxian Street, Nanjing, China 